\title{
El inventario de patrimonio industrial: el ejemplo francés. Metodología y estado de la cuestión
}

\author{
The Industrial Heritage inventory: the French \\ example. Methodology and state of the question
}

María ZAPICO LÓPEZ

Universidad de Nantes

RESUMEN: El presente texto ofrece una síntesis de los acontecimientos que estuvieron en los orígenes de la valorización de la herencia industrial, los cuales sentaron las bases del estudio e inventario del patrimonio industrial a partir de la década de 1970 en Francia. El análisis se centra, además, en las primeras tentativas experimentales en materia de inventario así como en la reflexión sobre la construcción de una metodología específica para el patrimonio industrial. En último lugar, se aborda la elaboración del inventario en la actualidad, una vez que las competencias de inventario han sido transferidas a las regiones de Francia. Este hecho ha significado la apertura de nuevos horizontes para su difusión a través de novedosas herramientas.

Palabras clave: Patrimonio industrial, Inventario, Registro, Francia, Metodología.

ABSTRACT: The text presented here provides a synthesis of the events that involved in the beginnings of Industrial Heritage valorization which formed the basis of the study and inventory of Industrial Heritage in the 1970s in France. Moreover, the analysis focuses on the first experimental attempts in inventory, as well as reflection on the construction of a specific methodology for the Industrial Heritage. Finally, inventory development is addressed at the present time when the inventory competences have been transferred to the regions of France, which means opening new horizons for dissemination through innovative tools.

Keys words: Industrial Heritage, Inventory, Record, France, Methodology.

\section{DATOS HISTÓRICOS EN TORNO A LA CONSIDERACIÓN DE LA CUL- TURA INDUSTRIAL}

Los artilugios y establecimientos productivos, así como la memoria oral del trabajo que otorga al patrimonio industrial su di- mensión más humana y social, fueron excluidos durante décadas de la noción de herencia cultural en Francia ${ }^{1}$. Como ocurriera en gran

${ }^{1}$ Beneficiaria del Programa "Clarín" - Marie CurieCOFUND de Ayudas Postodoctorales del Principado de Asturias en la Universidad de Nantes. 
número de países de Europa, los testimonios materiales de la actividad industrial fueron víctimas del desprecio, quedándose fuera de los márgenes del término patrimonio ${ }^{2}$. Sin embargo, a partir de la década de 1970 se percibe una tímida toma de conciencia en el seno de la sociedad francesa. Paulatinamente se fue gestando un ambiente proclive hacia la preservación de un patrimonio, el industrial, sin el cual sería casi imposible llegar comprender en profundidad la historia de los dos últimos siglos ${ }^{3}$. En este sentido, el movimiento de valorización del patrimonio industrial en Francia comenzó a hacerse un hueco en un contexto económico y social muy preciso, marcado por la crisis económica iniciada con el fin de los Treinta Gloriosos. Se trataba de

\footnotetext{
${ }^{2}$ Un caso aparte lo constituye Gran Bretaña, territorio en el que se manifiesta, en primer lugar, la preocupación por la conservación e inventario de los restos industriales del pasado. Una de las singularidades de este proceso, a diferencia de otros países europeos, fue el enorme respaldo popular de estas iniciativas que precedió a la toma de conciencia sobre la industrialización desde el ámbito académico. En lo que se refiere en concreto a la labor de registro e inventario de los elementos evocadores del pasado industrial, contó con su mayor desarrollo a partir de la década de 1950. No obstante, no se llegó a esta coyuntura de manera espontánea sino que vino precedida de un valioso trabajo en cuestiones de inventario que brevemente mencionaremos. Llegada la década de 1950 se multiplicaron las propuestas a favor de la protección del patrimonio industrial. De este modo el Council for British Archeaology (CBA), nacido en 1944, creó, en 1959, el Research Committee on Industrial Archaeology. Uno de los puntos de inflexión lo supuso la destrucción de numerosos ejemplos del patrimonio industrial, como fue el caso del pórtico de Euston Station en 1963. Ante esta situación apareció, ese mismo año, el Industrial Monuments Survey que, aunque financiado por el Ministry of Public Buildings and Works, estaba gestionado por el CBA y cuyo primer survey officer fue Rex Wailes. En B. MALAWS, "Process Recording at Industrial Sites", Industrial Achaeology Review, no 19, 1997, pp. 75-98; K. FALCONER, "The industrial heritage in Britain - the first fifty years", La Revue pour l'Histoire du CNRS (en línea), no14, Mayo 2006, consultado el 10 de diciembre de 2014. URL: http://histoire-cnrs.revues.org/ document1778.htm y M. PALMER y P. NEAVERSON, Industrial Archaeology. Principles and practice, New York, 1998, sin paginar.
}

${ }^{3}$ Acerca de este proceso de sensibilización puede consultarse: L. BERGERON y G.DOREL-FERRÉ, Le Patrimoine Industriel. Un nouveau territoire, París, 1996. un momento convulso en el que acontecen la desindustrialización y la reconversión industrial. Además, se comenzaba a vislumbrar un cambio profundo en el paisaje industrial debido a la destrucción de numerosos vestigios, como es el caso de Les Halles, un mercado mayorista de París diseñado por Victor Baltard. En este escenario, la revista Monuments Historiques dedicó un número a los lugares del trabajo en el cual ponía en tela de juicio el concepto de patrimonio en su acepción clásica ${ }^{4}$. A ello habría que añadir una serie de actuaciones significativas desde el ámbito académico, asociativo y público francés que irán conformando un ambiente propicio para la aparición del registro sistemático y salvaguarda de la cultura industrial. En este sentido, se fueron desarrollando y concatenando una serie de intervenciones, tanto desde el medio público como desde la sociedad civil, cuyo denominador común era la voluntad de poner en valor los vestigios de la industrialización en Francia. Entre ellas encontramos, nuevamente en la década de 1970, la pilotada por la figura de Maurice Daumas ${ }^{5}$, especialista en historia de las técnicas. Daumas impulsó la creación del Centre de Documentation d'Histoire des Techniques (CDHT) encargado de realizar en ese momento un estudio sobre edificaciones del país galo de los siglos XVIII y XIX6.

Otro hecho significativo lo constituyó la creación del Écomusée du Creusot por parte de Marcel Evrard, escenario, en 1976, del congreso internacional titulado Patrimoine industriel et societé contemporaine ${ }^{7}$. Desde

${ }^{4}$ C. DEVILLERS, “L'architecture industrielle ou la crise du monument historique", Monuments Historiques, no3, 1977, pp. 1-5.

${ }^{5}$ Maurice Daumas escribió la primera síntesis sobre la arqueología industrial en Francia: M. DAUMAS, L'archéologie industrielle en France, París, 1980.

${ }^{6}$ Aunque este estudio tuvo escasa difusión, ayudó a tomar conciencia del aislamiento que padecían los investigadores en esta nueva materia. M. DAUMAS, (dir.), Les bâtimentes à usage industriel aux XVIII et XIX siècles en France, París, 1978.

${ }^{7}$ En marcha desde 1972, bajo la denominación Musée de l'Homme et de l'Industrie, fue uno de los primeros 
esta institución, además, se llevó a cabo un inventario sistemático de edificios civiles e industriales en 16 municipios de la comunidad urbana de Creusot-Montceau-les Mines ${ }^{8}$.

De modo paralelo empezó a ser ensalzada la propia estética del objeto industrial a través de exposiciones o trabajos artísticos relacionados, especialmente, con la fotografía. Estas muestras, sin duda, resultaron de gran ayuda para sensibilizar a la sociedad apelando al sentimiento de emoción colectiva al rememorar un pasado industrial común y, con ello, la necesidad de preservar$l^{9}$.

Desde otro punto de vista, sería incompleto efectuar un repaso sobre los pioneros de la puesta en valor del patrimonio industrial en Francia sin tener en cuenta la contribución del medio asociativo, especialmente de la CILAC (Comité d'Information et de Laison pour l'Archeologie, l'étude et la mise en valeur du patrimoine industriel $)^{10}$. Se trata

en Francia en contar con el calificativo de ecomuseo, junto con Landes de Gascogne. Los estatutos del museo se remontan a octubre de 1973; por su parte, la reunión inaugural tuvo lugar en diciembre de ese mismo año, aunque oficialmente el museo se constituye el 15 de abril de 1974. Sobre el Museo de Creusot es de obligada consulta su página web, consultada el 12 de febrero de 2015. URL: http://www.ecomusee-creusot-montceau.fr/

${ }^{8}$ Estudio que, por otra parte, permitió probar una metodología encaminada a establecer un sistema de inventario. Inventaire national du patrimoine industriel français-élaboration d'une méthodologie. Écomusée de la communauté Le Creusot-Montceau-les-Mines. École nationale des travaux publics de Vaulx-en-Velin. Rapport rédigé par des élèves de l'ENTPE, julio, 1981.

${ }^{9}$ Entre estas exposiciones podemos nombrar la itinerante conocida con el título: "L'usine, travail, architecture", que tuvo lugar en 1973 cuyas obras pueden ser consultadas a través de la publicación: V. GRENIER , $L^{\prime}$ usine : travail et architecture : 24 mai-15 sept. 1973, Catálogo de Exposición, Centre de création industrielle, Pavillon de Marsan, París, 1973. También de suma importancia fue el compendio fotográfico de la industrialización reunido por Lise Grenier y Hans Wieser. L. GRENIER y H. WIESER-BENEDETTI, Recherches sur l'architecture de la région lilloise de 1890 à 1930: Les châteaux de l'industrie, París-Bruselas, 1979.

10 La CILAC asume la edición de la revista L'Archéologie industrielle en France, de obligada consulta de una asociación fundada en $1978^{11}$ que ha venido jugando un papel determinante en lo que se refiere al estudio y valorización del patrimonio industrial ${ }^{12}$.

En lo que se refiere a la emergencia del patrimonio industrial también tuvieron una posición concluyente los poderes públicos, cuya acción comienza a ser palpable en los momentos finales de la década de 1970. En este sentido, en el seno de la secretaría de Estado para la Investigación, nace la Mission Interministérielle de l'information scientifique et technique (MIDIST), en septiembre de 1979. Su principal propósito era el de pilotar una acción de enorme envergadura a nivel nacional, destinada a trasmitir la cultura industrial, científica y técnica entre el gran público. Igualmente pretendía lograr una mejor comprensión de la tecnología como clavija y motor de nuestra sociedad utilizando diversas herramientas, como la intensificación de publicaciones en este ámbito.

Sin embargo, aunque estos antecedentes reforzaron la posición del patrimonio industrial, la verdadera movilización del Estado francés se dejó sentir de modo más profundo a partir de la década de 1980. En aquel entonces, la valorización del patrimonio industrial llegó a convertirse en una política cultural a nivel nacional. Tal es así que, en 1981, tuvo lugar una importante co-

para aproximarse a los orígenes del inventario de patrimonio industrial en Francia, así como su estudio y análisis también en la actualidad, como puede consultarse en URL: http://www.cilac.com/

${ }^{11}$ No tendrá personalidad jurídica hasta mayo del año siguiente, 1979.

${ }^{12}$ Bajo sus siglas confluyen varios actores: la investigación universitaria, la nueva museología (Museo de Le Creusot) y el medio empresarial. Personajes como Louis Bergeron, director de estudios en el EHESS (École des hautes études en sciences sociales) o Yves Malécot, antiguo presidente de la Caisse nationale des monuments historiques, aseguraban la diversidad de campos de proveniencia de sus miembros, presentando como voluntad reunir a investigadores e instituciones con vocaciones diversas pero complementarias. A. BERNARD, "Les débuts du CILAC", Historiens \& Géographes, nº 405, 2009, pp.153-158. 
laboración entre la MIDIST y la Dirección de Patrimonio con la intención de que fuese creada una Misión de Patrimonio Industrial integrada por J.F. Belhoste y G. Emptoz ${ }^{13}$. Fruto de esta cooperación se esperaba alcanzar un consenso encaminado a obtener propuestas al objeto de crear un inventario de patrimonio industrial. Por este motivo, entre sus propósitos estaba elaborar un estado de la cuestión, un diagnóstico general, profundizando en el entendimiento y naturaleza específica de este patrimonio. Otra de las metas era hacer un análisis sobre los agentes directamente relacionados con esta clase de patrimonio, tales como asociaciones de salvaguarda, servicios regionales de inventario, museos técnicos o centros universitarios.

A partir de las conclusiones extraídas de este examen quedaron latentes algunas lagunas presentes en el Inventario general que suponían un lastre a la hora de acometer con éxito el inventario del patrimonio industrial. Por ejemplo, no existían puntos de referencia a la hora de definir los criterios de descripción de objetos, máquinas y edificios, es decir, de establecer un vocabulario técnico para el censo y la encuesta. Pero también quedó patente la importancia de combinar la colaboración de los medios científicos, asociativos y del Inventario general para poder llegar a confeccionar un inventario documentado de este tipo de patrimonio.

En 1983, apoyada en estos cimientos, y como continuidad de la Misión de patrimonio industrial, nace la Cellule du Patrimoine Industriel. Dependiente de la Subdirección del Ministerio de Cultura del Inventario General de los Monumentos y las riquezas artísticas de Francia, su particularidad estribaba en estar consagrada específicamen-

\footnotetext{
${ }^{13}$ Jean-François Belhoste se encargaba de la investigación sobre ingeniería en la sub-dirección del Inventario, aunque en la actualidad ocupa el cargo de director de estudios en la EPHE (École pratique des hautes études), en París. En lo que concierne a Gérard Emptoz, en la actualidad es profesor emérito de la Universidad de Nantes, habiendo recibió formación como químico e historiador de la innovación tecnológica; también formó parte de la subdirección del Inventario.
}

te al estudio del patrimonio industrial. Este acontecimiento supuso un hito, puesto que ampliaba la noción de patrimonio dentro de las fronteras del Inventario general que André Malraux concibió en $1964^{14}$. Hasta aquel entonces los espacios productivos se encontraban fuera del campo de estudio del Inventario general. La fábrica no era considerada como un elemento patrimonial $y$, aunque encontramos alguna excepción, su inclusión respondía a su calidad arquitectónica más que a criterios técnicos e industriales. Así, a partir del surgimiento de la Célula de Patrimonio Industrial, el Inventario general amplió su campo de acción, dando lugar a una noción más abierta y transversal de patrimonio, emergiendo el concepto de patrimonio cultural.

A partir de entonces, los vestigios de la industrialización comenzaron a ser inventariados, estudiados $\mathrm{y}$, según los casos, protegidos. Dentro de un mismo dispositivo metodológico y marco jurídico que los ejemplos que podríamos denominar como clásicos o cultos.

De otro lado, una vez surgida la Célula de patrimonio industrial, quedaron patentes ciertas rémoras que debían de ser subsanadas. Entre ellas podemos citar la falta de especialistas formados en cultura técnica e industrial ${ }^{15}$, sin olvidar la inexistencia de fichas de encuesta adaptadas al patrimonio industrial y técnico. Con todo, en el seno de la Célula se fueron elaborando una serie de medidas orientadas al estudio del patrimonio industrial, entre las que encontramos la configuración de herramientas de inventario

\footnotetext{
${ }^{14}$ El Inventario General de Francia constituye un servicio nacional creado por Decreto de 4 de marzo 1964 de la mano de André Malraux; inicialmente se concibió para censar y estudiar los monumentos y riquezas artísticas de Francia, quedando excluidos, por ejemplo, los vestigios del pasado industrial. En M. MELOT, "Le grand inventaire“, In Situ (en línea), no 6, 2005, consultada el 9 de marzo de 2015. URL : http://insitu.revues. org $/ 8797$

${ }^{15}$ Hasta aquel entonces, el Inventario general se nutría de historiadores del arte poco familiarizados con la arquitectura y la producción industrial.
} 
adaptadas a este patrimonio específico. A ello habría que unir la fijación de una serie de parámetros que sirvieron de referencia en el censo de los vestigios industriales, así como la toma en consideración de nuevas áreas de conocimiento relacionadas con la historia de las técnicas o la economía. Se constituyó, además, una red para el estudio del patrimonio industrial alrededor de todo el país y se fueron elaborando estudios temáticos relacionados con la cultura industrial, en colaboración con el medio universitario.

Tres años después de su creación, en 1986, la Célula lanzó un inventario nacional de elementos de la industria gracias a la actuación sobre el terreno de los servicios regionales del Inventario general. Una de las mayores ambiciones de este inventario residía en la rapidez relativa con la que debería ser llevado a cabo. Se trataba de un patrimonio en peligro inminente de desaparición debido a las reestructuraciones industriales y las mutaciones tecnológicas ${ }^{16}$. Para comenzar, se tomó la decisión de lanzar la experiencia de inventario sobre cuatro regiones a título experimental: Champagne-Ardenne, Basse-Normandie, Poitou-Charentes y Picardie. Asimismo, con el fin de perfeccionar la metodología y para armonizar los resultados de encuesta de las regiones, la célula procedía regularmente a realizar un balance de los trabajos en curso. Estos encuentros eran la ocasión para discutir y solucionar dificultades encontradas.

Con posterioridad, en 1993, la célula extendió su campo de estudio y comenzó a ocuparse del patrimonio científico y técnico, con lo que pasaba a tener en cuenta los observatorios astronómicos, el patrimonio ferroviario o el médico. Al año siguiente, se incorpora el censo de maquinaria integrada en los bienes inmuebles, completando la descripción de los bienes industriales. Finalmente, la Célula de Patrimonio Industrial desaparece en 1995.

${ }^{16}$ J. F. BELHOSTE y P. SMITH, Patrimoine industriel, cinquante sites en France,"Images du patrimoine", París, 1997, p. 10.
De otro lado, un hecho de enorme relevancia, en lo que se refiere al patrimonio técnico e industrial, fue el acercamiento que tuvo lugar entre el servicio de Inventario general y el de Monumentos históricos entre 1991 y 1995. Esta colaboración tenía por objeto elaborar un análisis sobre los sistemas de selección que desembocarían en la protección y entendimiento del propio objeto patrimonial ${ }^{17}$. Siempre dentro de este contexto de protección del patrimonio industrial también se inscribió la Misión Loiseau, dirigida por el Préfet Philippe Loiseau, ex-presidente de las Houillères $d u$ bassin de Lorraine, en los años centrales de la década de 1990. Como resultado de una serie de reuniones se concluyó un informe encaminado a alentar el debate y mejorar la calidad de las políticas, en forma de estrategia nacional de salvaguarda y valorización en materia de protección del Patrimonio industrial $^{18}$.

Por último, cabe reseñar la importancia que para el estudio en profundidad de la cultura industrial ha tenido la instauración de la Ley de 13 de agosto de 2004 relativa a las libertades y responsabilidades locales ${ }^{19}$. A partir de su entrada en vigor el día 1 de febrero de 2007, el inventario de patrimonio cultural, y por consiguiente el patrimonio industrial científico y técnico, fue transferido a las regiones.

${ }^{17}$ Otro hecho destacable fue la creación de la cuarta sección de la Comisión Nacional de Monumentos Históricos en el año 1985. Su cometido, hasta su desaparición en 2007, era la evaluación de los expedientes relativos al patrimonio industrial, lo cual aumentó la intensidad y la premura de la protección de edificios industriales. M. GASNIER, Patrimoine Industriel et Technique Perspectives et retour sur 30 ans de politiques publiques au service des territoires, "Cahiers du Patrimoine", no 96, Lyon, 2011, p. 257.

${ }^{18}$ Ibídem, p. 108.

${ }^{19}$ Loi n²004-809 du 13 août 2004 relative aux libertés et responsabilités locales, capítulo II, artículo 95, consultada el 20 de diciembre de 2014. URL : http://www. legifrance.gouv.fr/affichTexte.do?cidTexte=JORFTEXT000000804607 
ASPECTOS METODOLÓGICOS $Y$ NUEVAS PERSPECTIVAS PARA EL INVENTARIO DEL PATRIMONIO INDUSTRIAL

En lo que respecta a la metodología del inventario aplicada a descubrir y analizar los bienes industriales, lo que inicialmente se hizo fue trasladar los principios básicos del Inventario general. Debía, además, tratarse de una metodología sólida, capaz de perdurar en el tiempo. De ahí la importancia de que sus herramientas fueran coherentes con el Inventario general, compatibles con las bases de datos de arquitectura y objetos muebles ya existentes. Parece oportuno, por tanto, comenzar haciendo una aproximación a los principios que rigen el Inventario general, para después centrarnos en la metodología concreta del inventario de patrimonio industrial.

Desde el momento de su aparición, en 1964, el Inventario general se presentó como un actor esencial, constituido con el fin de realizar el censo sistemático del conjunto del patrimonio mueble e inmueble. Entre sus cometidos estaban establecer los métodos de inventario y estudio; además de fijar las referencias científicas y la configuración de una red de investigadores especializados en cada una de las regiones ${ }^{20}$.

La labor de inventario efectuada se basa principalmente en la dualidad de modos de acercamiento al objeto o sitio en cuestión: el inventario y el estudio. Estos pueden ser empleados en paralelo y aplicados sucesivamente sobre diversas áreas de estudio con la finalidad de obtener los datos necesarios referentes a la identificación, localización, datación, autor e imagen. Entre las

\footnotetext{
${ }^{20} \mathrm{Su}$ nota definitoria, y a la que debería adaptarse el inventario de patrimonio industrial, era su carácter científico visible en la fijación de protocolos que permiteran organizar la investigación, darle coherencia y homogeneidad, así como los que permiten transcribir unos resultados acumulables y comparables. Véase M. MELOT y H. VERDIER (dirs.), Principes, méthodes et conduite de l'inventaire général, "Documents \& Méthodes", no 9, París, 2001, p.182-184.
}

características que mejor definen el inventario en Francia están la normalización de una descripción estructurada y el empleo de un vocabulario riguroso. Estas herramientas permiten guiar la lectura de los objetos y hacerlos comparables entre ellos. Asimismo, la importancia que se ofrece a la ilustración gráfica y fotográfica, la teorización, la articulación entre texto e imagen, integran una metodología descriptiva razonada.

Si nos centramos ahora en el trabajo concreto a realizar por el investigador en el momento de enfrentarse al inventario, el Inventario general ofrece algunas directrices a seguir. Por ejemplo, aconseja, inicialmente, hacer un acercamiento a bibliotecas y archivos con la finalidad de recabar información básica sobre el objeto a inventariar, para, en un momento posterior efectuar, el trabajo de campo. Sin embargo, el verdadero punto de partida tiene lugar sobre el terreno, donde los investigadores recorren las localizaciones para constatar con precisión cuáles son los elementos que todavía perviven y van a ser incluidos en el inventario. Durante esta fase del trabajo de campo, los técnicos se sirven de diversos instrumentos metodológicos que estructuran y armonizan la documentación. Entre ellos, la ficha de encuesta, una doble hoja donde se aglutinan y se pone en orden la información útil recogida en cada sitio. En un momento posterior, las precisiones descriptivas e históricas se verifican en los archivos. Con todo, se procede a la apertura de un dosier, correspondiente a cada uno de los repertorios estudiados. El producto final, que incluye texto y fotografías, hace alusión a referencias documentales, localización, comentario histórico, características morfológicas y protección. A este respecto, se pusieron en marcha una serie de recursos técnicos encaminados a la difusión y valorización de los datos inventariados del patrimonio a través de un dosier electróni$\mathrm{CO}^{21}$. Fruto de este ansia de divulgar las con-

\footnotetext{
${ }^{21}$ Originalmente el objetivo de trabajo del inventario consistía en establecer un dosier manuscrito por obra estudiada compuesto de imagen y texto.
} 
clusiones extraídas en la fase de registro nació la herramienta conocida como Renabl22, en la década de 1990.

De otro lado, las conclusiones extraídas de las operaciones científicas derivadas del inventario general se difunden a través de diversas publicaciones ${ }^{23}$. Junto a ellas, el resultado de las actuaciones del Inventario general se puede consultar en línea a través de las bases de datos Architecture - Mérimée, para el patrimonio mueble, y Mobilier-Palissy, para el inmueble ${ }^{24}$.

${ }^{22}$ Renabl, que significa inventario en bretón, fue utilizado por primera vez, al objeto de integrar los datos referentes al inventario de patrimonio industrial, en la Región de Bretaña, en 1999. Esta herramienta permitía tratar las obras de todos los campos patrimoniales, muebles o inmuebles de manera topográfica o temática. Ofrecía nuevas posibilidades en la explotación de los datos recolectados donde texto, cartografía, bibliografía, recursos archivísticos e iconográficos pueden ser explotados de manera interactiva a través de un desarrollo de enlaces de hipertexto. El manual de utilización del dosier electrónico Renabl puede ser consultado en línea, consultado el 7 de enero de 2015. URL: http:// www.culture.gouv.fr/culture/inventai/telechar/renabl/ manuel_renabl.pdf

${ }^{23}$ Entre las publicaciones impresas, podemos enumerar: Cahiers du patrimoine, Corpus vitrearum, Images $d u$ patrimoine, Indicateurs du Patrimoine, Parcours du patrimoine y junto a ellas encontramos las relativas a las normas del Inventario general entre las que se encuentran: Principes d'analyse scientifique o Documents \& Méthodes. El catálogo de publicaciones puede ser consultado en línea, consultado el 6 de enero de 2015. URL: http://www. culture.gouv.fr/public/mistral/dapapub_fr?ACTION=R ETOUR\&USRNAME $=$ nobody\&USRPWD $=4 \$ 4 P$. Véase además: I. BALSAMO, C. GROS y H. VERDIER (dirs.), Les publications de l'Inventaire général du patrimoine culturel, “Documents \& Méthodes", nº11, París, 2007, p.25.

${ }^{24}$ Las fichas de inventario pueden ser visualizadas en los siguientes enlaces, consultados el 20 de febrero de 2015. URL://www.culture.gouv.fr/public/mistral/merimee_fr?ACTION=NOUVEAU\&USRNAME $=$ nobody \&USRPWD $=4 \% 24 \% 2534 \mathrm{P}$ y http://www.culture.gouv. fr/public/mistral/palissy_fr?\&FIELD_98=DMIS\&VALU E_98 $=2015 \% 2$ b\&USRNAME $=$ nobody \&USRPWD $=4 \% 2$ 4\%2534P\&REL_SPECIFIC $=9 \& I M A G E \_O N L Y=\& R E L$ SYNONYMOUS $=1 \& A C T I O N=$ RETOUR. Parece pertinente precisar que, si bien estas bases de datos constituyen una herramienta informática un tanto obsoleta, el Inventario francés fue el primero en crear bases de datos y jugar un rol pionero en este dominio.
En lo que respecta a la construcción de la metodología de inventario de patrimonio industrial, en líneas generales, el método se asimiló al comentado para el Inventario general $^{25}$.

Con todo, la elaboración de una metodología específica para el patrimonio industrial se sustentó sobre cuatro pilares ${ }^{26}$ : la configuración de una ficha de inventario de patrimonio industrial; la confección de un léxico jerarquizado y normalizado así como la construcción de una maqueta informática y la redacción de un libro de utilización.

En lo que atañe al desarrollo del modelo de ficha de inventario, se tomaron como referencia las instrucciones de indexación existentes para la arquitectura. A partir de aquí, en 1986, una serie de especialistas en patrimonio del Inventario general colaboraron con el fin de definir y estipular los campos que debían de integrar la hoja de registro $^{27}$. El resultado fue el de una tabla a cumplimentar que incluía numerosos campos preestablecidos, al objeto de aunar las principales características de un sitio industrial. Se incluyó una pequeña reseña histórica, referencias a la localización, a su autoría o referencias documentales y bibliográficas e ico-

${ }^{25}$ C. CARTIER, P. SMITH y C. CHAPLAIN, “Le repérage du patrimoine industriel en France: objectifs et méthode", en Actes du Colloque europeén organisé par el Conseil de l'Europe et le ministère français de l'Education nationale et de la Culture- Direction du patrimoine, "Patrimoine culturel", no 28, Nantes, 1993, pp.99-106.

${ }^{26}$ En la actualidad, el Inventario General de Patrimonio Industrial puede ser consultado a través de internet a través del siguiente enlace, consultado el 13 de enero de 2015. URL : http://www.inventaire.culture. gouv.fr/Chemin_patind.htm

${ }^{27}$ Es así como su constitución se apoyó en el análisis comparativo con numerosas tablas francesas y extranjeras. Para ello se tomaron en cuenta dos tipos de tablas, de una parte las que trataban el patrimonio industrial en su conjunto y, en segundo lugar, las concernientes a un inventario de tipo específico de sitio industrial o rama de la actividad. Para todo lo relacionado con las herramientas metodológicas del inventario de patrimonio industrial en Francia es de obligada consulta la obra: M. GASNIER, Op.cit., pp.59-69. 
nográficas ${ }^{28}$. A grandes rasgos, la morfología de la ficha ha sido conservada hasta la actualidad, solamente se han ido incorporando algunos campos en un intento por hacerla más completa y dinámica. Quedó distribuida en 11 secciones: la primera titulada referencias documentales y la segunda, denominación. Entre el tercer y quinto apartados, se precisaba la localización, la época de construcción o el nombre del artífice de la obra, para después tratar cuestiones relacionadas con la fuente energética ${ }^{29}$. En sexto lugar, encontramos el campo relativo al comentario histórico; tanto entonces como en la actualidad, se trata de un campo libre, abierto, pero con caracteres limitados. Aunque este campo es común en todos los objetos del Inventario general, en el caso del patrimonio industrial presenta alguna peculiaridad. Tal es así que hallamos una subdivisión en tres apartados: el primero, destinado a reconstruir sucintamente la historia del sitio. Se referencian aquí aspectos relativos a su creación, su evolución, sus múltiples destinos, sus diversas fases constructivas, los tipos de producción o la fecha en la que cesa la actividad. A continuación, un segundo espacio se consagra a la dimensión técnica ${ }^{30}$. Y por último, la tercera parte aborda la cuestión social. En ella tiene cabida todo lo relacionado con el personal en las diversas épocas de implantación de las Sociedades. Se mencionan las huelgas importantes o cualquier elemento relacionado con el paternalismo industrial, tales como cooperativas, alojamientos o comedores.

\footnotetext{
${ }^{28}$ Se profundizaba en aspectos tales como el emplazamiento, vocabulario arquitectónico o maquinaria. Para todo el párrafo véase M. F. FERNÁNDEZ GUTIÉRREZ, "La labor de inventario del Patrimonio Industrial en Francia. Un modelo de investigación, protección y difusión", Revista Ábaco, no 19 (Segunda época), 1998, pp. 59-70.

${ }^{29}$ En un primer momento, la cuestión de las máquinas de producción no fue tratada más que a través de una sola sección enriquecida con un comentario técnico.

${ }^{30}$ En el caso que fuese necesario son mencionadas precisiones sobre la utilización de las diferentes fuentes de energía, de los medios de transmisión, de procesos técnicos considerados como interesantes, precisiones sobre las máquinas si la presencia ha sido señalada.
}

De otro lado, la séptima y octava secciones de la ficha, tratan de las características arquitectónicas del establecimiento. Como colofón, los tres últimos capítulos, encaminados a una eventual protección, hacen referencia al estado de conservación del sitio, su estatus jurídico y el interés de la obra.

Otra aportación significativa, fue la confección de una ficha de conjunto. En ella, las diferentes partes que integran el sitio industrial son, además, estudiadas y tratadas en una ficha individual ${ }^{31}$.

El siguiente instrumento metodológico en la configuración del inventario de patrimonio industrial fue fijar, también en 1986, un léxico jerarquizado; un vocabulario armonizado y normalizado, común para el conjunto del país. A ello se sumó la concepción de un programa informático, especialmente ideado para servir a este patrimonio. En último lugar, se redactó una especie de guía práctica, destinada a servir de orientación a la hora de cumplimentar las fichas de inventario. La redacción de la primera versión se realizó en 1987 bajo el título $L i$ vret de prescriptions techniques pour le repérage du patrimoine industriel. Las directrices aquí incluidas versaban sobre diferentes tipos de léxico específico de patrimonio industrial. Además, encontramos algunas puntualizaciones metodológicas complementarias respecto al enfoque a seguir a la hora de llevar a cabo el inventario. Sin embargo, este escrito no contó con una gran difusión y ni siquiera fue objeto de publicación.

Como se apuntaba con anterioridad, la labor de inventario estuvo centralizada,

\footnotetext{
${ }^{31}$ A este respecto, se presentó la posibilidad de elaborar un sub-dosier de cada una de las partes constituyentes para, de este modo, asegurar las interrelaciones entre las diversas unidades de producción geográficamente distintas, aunque inscritas bajo la misma razón social. Para una armonía mayor la noción de conjunto fue definida para los sitios industriales extensos, complejos y fragmentados en parcelas distintas, separados los unos de los otros, pero sin embargo ligados por sus funciones industriales y su pertenencia a una época determinada, a un mismo industrial o una misma empresa.
} 
dependió del Estado hasta la aparición de la Ley no 2004-809 de 13 de agosto de 2004, relativa a las libertades y responsabilidades locales, vigente en la actualidad. De este modo, las competencias en materia de inventario se han traspasado a las regiones, las cuales deben elaborar un informe sobre las operaciones llevadas a cabo según los principios del Inventario general, aunque sometidas a control científico del Estado. Así, este define las normas, asegurando el control científico-técnico, y las regiones deciden la programación de las operaciones, esto es, garantizan su desarrollo individualmente o en un marco de cooperación.

Por lo tanto, la aparición de esta nueva ley ha supuesto la ruptura de la hegemonía del Estado en materia de inventario y un reparto de responsabilidades. En este sentido, las regiones han pasado a tener mayor autonomía a la hora de priorizar unos temas sobre otros y el estudio de unos territorios sobre otros. Tal es así, que la libertad de acción, en lo que comporta al inventario de patrimonio industrial, podría suponer un beneficio a la hora de ampliar su campo de estudio al patrimonio inmaterial, por ejemplo $^{32}$.

En lo que respecta a las labores de inventario de patrimonio industrial en Francia en los últimos diez años, cabe decir que los trabajos se han desarrollado de manera irregular, dependiendo del ámbito geográfico y de los recursos. Uno de los principales inconvenientes observados, una vez transferidas las competencias, ha sido la falta de

\footnotetext{
${ }^{32}$ Como muestra, resulta interesante la propuesta de inventario de la memoria obrera lanzada en la región de Poitou-Charentes en 2009. Al objeto de restituir la dimensión humana al patrimonio industrial en la región, se han recogido, en diferentes formatos (video, iconográfico, textual y sonoro) testimonios de trabajadores para salvaguardarlos y ponerlos a disposición del público. Véase el sitio web, consultado el 10 de abril de 2015. URL: https://inventaire.poitou-charentes.fr/operations/ les-memoires-ouvrieres/103-les-memoires-ouvrieres. Otro ejemplo de testimonios de trabajadores se puede encontrar en la web de Pays de la Loire, consultada el 10 de abril de 2015. URL: http://www.patrimoine.paysdelaloire.fr/multimedia/temoignages/
}

correspondencia entre las fronteras territoriales de los departamentos franceses y la lógica de la industrialización. Es decir, las demarcaciones del territorio regional no se corresponden con la disposición de los recursos minerales ni con los circuitos comerciales del momento industrial. Entre las primeras regiones en finalizar el inventario de patrimonio industrial en Francia están Poitou-Charentes, en 2007, y Champagne-Ardenne, en $2009^{33}$. Por otro lado, se trata de dos de las regiones en las que se ensayó de modo experimental la metodología de inventario de patrimonio industrial en 1986.

En otro orden de cosas, uno de los puntos que estipula la Ley no ${ }^{2}$ 2004-809 de 13 de agosto de 2004 es que los datos resultantes del inventario en el seno de las Regiones, deben ser volcados en el sitio web del Ministerio de Cultura, para su difusión. Sin embargo, las bases de datos nacionales Mériméé y Palissy parecen difícilmente responder al dinamismo esperado para la divulgación, explotación $\mathrm{u}$ organización de noticias ${ }^{34}$. Estas bases se suelen colapsar por lo que, con el fin de garantizar una mayor interactividad, se han constituido sitios web independientes por parte de las regiones, donde puede ser consultado su patrimonio cultural ${ }^{35}$. Una de las páginas más interesantes es la de la re-

33 Véase la web, consultada el 12 de marzo de 2015. URL: http://www2.cr-champagne-ardenne.fr/ patrimoineindustriel08/

${ }^{34}$ Cabe preguntarse si, hoy por hoy, constituyen una herramienta útil de explotación científica, concebida inicialmente más como un espacio de almacenamiento, de organización de datos, que como un objeto con vocación científica. Estamos ante bases un tanto estáticas, que no se corresponden con los usos actuales, que contienen dosieres documentales a veces pobres, incluso con noticias desprovistas de ilustraciones.

${ }^{35}$ Algunos servicios regionales muestran su preferencia por el sistema centralizado anterior a la transferencia de competencias a las regiones, augurando un futuro en el que las páginas web regionales de patrimonio darán paso a una único sitio web nacional en el que se puedan poner en relación los resultados del conjunto del país. 
gión Poitou-Charentes ${ }^{36}$, la primera en llevar a buen término el inventario de patrimonio industrial en 2007. Como peculiaridad, presenta un dosier en línea exclusivamente consagrado al patrimonio industrial ${ }^{37}$. En él se proponen numerosas síntesis ilustradas sobre la arquitectura, historia y procesos de los diferentes sectores de las actividades. Además, se pueden encontrar mapas dedicados al desarrollo de las vías de comunicación, dosieres documentales sobre alguna de las fábricas así como un espacio pedagógico.

En este sentido, parte de los esfuerzos de las regiones han estado orientados a la reflexión sobre la evolución de las propias barreras del inventario, en lo que se refiere a la difusión de los resultados y su valorización rápida, eficaz. Si bien las publicaciones siempre van a constituir una vía esencial de trasmisión, existen otros formatos para llegar al conjunto de la población, igual de eficaces y mucho más atractivos. Para ello se deben tomar en cuenta los recursos que nos ofrece el momento actual, como las nuevas tecnologías de la información y la comunicación o los sistemas de información geográfica (SIG). Una vez sobrepasada la primera década del siglo XXI estos mecanismos se presentan como los principales medios para diversificar y enriquecer el formato clásico de los artículos en papel que, si bien siguen siendo imprescindibles, llegan a un menor número de personas. Algunos ejemplos lle-

${ }^{36}$ Otros ejemplos destacables son: la página web de Pays de la Loire, consultada el 10 de abril de 2015. URL: http://www.patrimoine.paysdelaloire.fr/accueil/, la de Picardie, consultada el 11 de abril de 2015. URL: https:// inventaire.picardie.fr/ o la de Île de France, consultada el 11 de abril de 2015. URL: http://patrimoines.iledefrance.fr/.

${ }^{37}$ Sin duda, la propuesta de Poitou-Charentes resulta una manera atrayente de valorización del inventario de patrimonio industrial que puede ser consultada en internet. Consultada el 3 de abril de 2015. URL: http:// dossiers.inventaire.poitou-charentes.fr/le-patrimoineindustriel/. Otra de las iniciativas interesantes llevada a cabo en esta provincia la entraña la exposición fotográfica llevada a cabo en 2007, en la que se exponen los trabajos de los fotógrafos del inventario en este departamento. vados a cabo con éxito son exposiciones o visitas virtuales, de temática relacionada con la industrialización, o los museos imagina$\operatorname{rios}^{38}$.

En lo que respecta al dosier electrónico, se ha constatado la inadecuación al momento actual de la herramienta de producción y difusión de conocimientos del inventario, Renabl. Por este motivo, dentro de la propia evolución inherente al inventario, tras la descentralización, se presentó como necesario desarrollar una nueva aplicación. De este modo, al amparo de una reunión inaugural acontecida en 2008 en el seno de las la Association des Régions de France, en París, se lanzó el proyecto identificado con el acrónimo Gertrude (Groupe d'Etude, de Recherche Technique, de Réalisation et d'utilisation du Dossier Electronique) ${ }^{39}$. El proyecto, puesto en marcha por los servicios regionales de inventario y las direcciones informáticas, tiene como objetivo definir, desarrollar y poner en servicio una solución de gestión y de difusión del dosier electrónico del Inventario de patrimonio cultural ${ }^{40}$. Se está confeccionando según las técnicas informáticas más actuales; esto permitirá ejecutar las actualizaciones pertinentes en función de los avances tecnológicos que se vayan produciendo.

A modo de conclusión, podemos establecer que, aunque la toma de conciencia sobre el patrimonio industrial en Francia fue un tanto tardía, las acciones posteriores encaminadas a su puesta en valor lo presentan como ejemplo de coordinación y exhaus-

${ }^{38}$ Resulta interesante el apartado de exposiciones virtuales del sitio web de Pays de la Loire, consultado el 12 de marzo de 2015. URL: http://www.patrimoine.paysdelaloire.fr/multimedia/expositions-virtuelles/ véase también URL: http://www.cnes-observatoire. net/memoire/musee_manif/01_jep05_patrimoine-espace/30.html

${ }^{39}$ M. GASNIER, Op.cit., p. 263.

${ }^{40}$ El proyecto todavía está en fase de desarrollo aunque se pretendía que estuviese desarrollado en todos los servicios de inventario en 2012. Se trata de una nueva herramienta concebida para responder de modo preciso a las necesidades de los investigadores y de usuarios en general. 
tividad. Su solidez y buenos resultados se han basado en la construcción de una metodología rigurosa de inventario a nivel nacional. Esta se sustenta gracias a su carácter científico, a la normalización de protocolos, así como gracias a la investigación de mecanismos de difusión. Este anhelo de homogeneizar protocolos perdura incluso después de que las competencias hayan sido trasferidas a las regiones, gracias al empeño de los servicios regionales por unificar criterios y mejorar las deficiencias del sistema. En contraposición a este modo de actuación en materia de inventario del patrimonio industrial encontramos el caso de España, donde existe un amplio abanico de modelos de ficha y de metodologías. Si bien se han hecho esfuerzos considerables en los últimos años en materia de registro, encontramos disparidad de criterios dependiendo de la entidades encarga- das de elaborarlos, de las políticas culturales o la legislación autonómica. Esta situación está contribuyendo a un conocimiento fragmentado y aislado del patrimonio industrial de cada una de las provincias donde se han efectuado los documentos de inventario sin consenso con otras regiones. Por este motivo, sería preciso valorar la posibilidad de elaborar un modelo de ficha única aplicable a todo el país, consensuada por las diferentes comunidades autónomas españolas. Del mismo modo, sería conveniente la elaboración de un catálogo nacional en red, basando sus parámetros en la uniformidad de términos y una coordinación entre las distintas entidades encargadas de hacer estos censos. Sin olvidar la puesta en común de nuevos métodos de difusión del inventario, para hacer llegar los resultados a un mayor número de personas dentro de la sociedad española. 